\title{
The relationship between motor function, cognition, independence and quality of life in myelomeningocele patients
}

\author{
Relação entre função motora, cognição, independência funcional e qualidade de vida em \\ pacientes com mielomeningocele \\ Carolina Lundberg Luz', Maria Clara Drummond Soares de Moura', Karine Kyomi Becker', Rosani Aparecida \\ Antunes Teixeira ${ }^{2}$, Mariana Callil Voos ${ }^{1}$, Renata Hydee Hasue ${ }^{1}$
}

\begin{abstract}
Motor function, cognition, functional independence and quality of life have been described in myelomeningocele patients, but no study has investigated their relationships. We aimed to investigate the relationships between motor function, cognition, functional independence, quality of life, age, and lesion level in myelomeningocele patients, and investigate the influence of hydrocephalus on these variables. We assessed 47 patients with the Gross Motor Function Measure (motor function), Raven's Colored Progressive Matrices (cognition), Pediatric Evaluation of Disability Inventory (functional independence) and the Autoquestionnaire Qualité de vie Enfant Imagé (quality of life).Spearman's correlation tests determined relationships between the variables. The Friedman ANOVAs determined the influence of hydrocephalus. Motor function was strongly related to mobility and lesion level, and moderately related to cognition, self-care and social function. Cognition and quality of life were moderately related to functional independence. Age correlated moderately with functional independence and quality of life. Hydrocephalus resulted in poorer motor/cognitive outcomes and lower functional independence.
\end{abstract}

Keywords: meningomyelocele; quality of life; cognition.

\section{RESUMO}

Função motora, cognição, independência funcional e qualidade de vida foram descritos em pacientes com mielomeningocele (MMC), mas sua correlação não foi investigada. Esse estudo investigou correlações entre função motora, cognição, independência funcional, qualidade de vida, idade, nível de lesão em pacientes com MMC e a influência da hidrocefalia nessas variáveis. Quarenta e sete pacientes foram avaliados com a Medida de Função Motora Grossa, Matrizes Progressivas de Raven, Inventário de Avaliação Pediátrica de Incapacidade e Autoquestionnaire Qualité de vie Enfant Imagé. Testes de Spearman investigaram as correlações. ANOVAS de Friedman investigaram a influência da hidrocefalia. A função motora correlacionou-se fortemente com mobilidade e nível de lesão e moderadamente com cognição, auto-cuidado e função social. Cognição e qualidade de vida correlacionaram-se moderadamante com independência funcional. Idade correlacionou moderadamente com independência funcional e qualidade de vida. Hidrocefalia associou-se a piores desfechos motores/cognitivos e menor independência funcional.

Palavras-chave: meningomielocele; qualidade de vida; cognição.

Myelomeningocele (MMC) is a form of spinal dysraphism resulting from a defective closure of the neural tube. It results in neuromusculoskeletal complications, including tetra- or paraparesis, neurogenic bowel and bladder, hydrocephalus, cognitive and behavioral issues. Higher levels of the MMC result in more severe neurological and orthopedic outcomes and are associated with more severe brain lesions, and motor and cognitive impairments ${ }^{1}$.

Many patients with MMC do not ambulate during infancy. A series of 53 children with MMC (from three to 11 years) was studied to see if the children with lower limb paresis would achieve the expected level of ambulation. Thirty-one of 53 children reached the expected ambulation according to their motor paresis. However, 22 performed worse than expected. Therefore, children with similar muscle paresis may exhibit distinct ambulatory function ${ }^{2,3}$.

Musculoskeletal immobility may contribute to social and cognitive delays ${ }^{4}$ and power mobility devices have been associated with a better cognitive and social development ${ }^{5}$.

1 Universidade de São Paulo, Faculdade de Medicina, Departamento de Fisioterapia, Fonoaudiologia e Ciências da Comunicação e Terapia Ocupacional, São Paulo SP, Brasil;

${ }^{2}$ Universidade de São Paulo, Instituto de Psicologia, São Paulo SP, Brasil.

Correspondence: Renata Hydee Hasue; Rua Cipotânea, 51; 05360-160 São Paulo SP, Brasil; E-mail: renatahhv@usp.br

Conflict of interest: There is no conflict of interest to declare.

Received 15 April 2016; Received in final form 11 September 2016; Accepted 15 April 2017. 
Roebroeck et al. ${ }^{6}$ described the relationship between cognitive function and lesion level in MMC. They found that higher levels were associated with poorer cognitive outcomes. The presence of Chiari malformation and hydrocephalus was associated with cognitive deficits ${ }^{7,8}$. A higher number of derivations influenced cognitive outcomes negatively 9

The cognitive and behavioral profile of patients with MMC has been described in a literature review, which evidenced deficits in timing, attention and motor processing. These impairments have been associated with cerebellar and brainstem lesions and, therefore, associated with brain malformations. Perception, verbal fluency, alliteration and mathematical reasoning difficulties have been reported ${ }^{10,11}$.

Motor and cognitive outcomes seem to influence the acquisition of mobility, which impacts development and adulthood independence ${ }^{7,8,10,11}$. Infants with MMC have difficulty acquiring self-care skills. Trunk control is essential for the acquisition of sitting, which allows the development of bimanual skills. Sirzai et al. investigated functional performance in children with different MMC levels, using the Pediatric Evaluation of Disability Inventory (PEDI) ${ }^{12}$. They considered the functional performance as low and concluded that low level lesions partially preserved muscle strength and independence in mobility, which were important factors for functional independence ${ }^{12}$.

Non-ambulating children with MMC have greater neurological and orthopedic symptoms and a lower quality of life than ambulating children. Wang et al. investigated the health-related quality of life in children with MMC. Scores were compared with a reference sample. The authors investigated the relationships between the lesion level and associated medical problems, with the quality of life. Patients with a MMC had lower scores on physical and psychosocial aspects. Children with a higher lesion level had poorer physical health, but not poorer psychosocial health ${ }^{13}$.

Studies have described the capacity, or lack thereof, of ambulation based on the lesion level, cognition, functional independence and quality of life separately, but no studies have described, simultaneously, gross motor function, cognition, functional independence and quality of life, or investigated their relationships in patients with MMC. The present study aimed to describe these variables and to investigate possible relationships. Also, this study aimed to assess the effect of hydrocephalus on gross motor function, cognition, functional independence and quality of life.

\section{METHODS}

\section{Patients}

Patients diagnosed with MMC, aged 6-20 years, who had had corrective neurosurgery at the Clinics Hospital of Faculty of Medicine of University of São Paulo were recruited ( $n=60$, convenience sample). Arnold-Chiari, hydrocephalus, congenital hip and/or knee luxation and/or clubfoot were allowed.
Exclusion criteria included other neurological lesions or malformations, kyphoscoliosis surgery or other recent surgery (less than six months before assessment). Fifty patients met the inclusion criteria and 47 patients and/or parents (for patients under 18 years old) gave informed consent to participate. This study was approved by the Ethics Committee of the Clinics Hospital.

\section{Procedure \\ Lesion level assessment}

The present study was an observational study. Patients were classified according to their lesion level as thoracic, high lumbar, low lumbar or sacral MMC. Patients with a thoracic level were scored as 1 , high lumbar level were scored 2 , low lumbar patients were scored as 3 and sacral lesions were scored as 4. This classification, with lower scores for more severe lesions, allowed the investigation whether the lesion level would influence other variables.

\section{Gross motor function assessment}

The Gross Motor Function Measurement quantified motor skills. The scale has five dimensions: A: lying and rolling (17 items); B: sitting (20 items); C: crawling and kneeling (14 items); D: standing (13 items); F: walking, running and jumping (24 items) $)^{14}$.

Each item is scored from 0 (cannot perform) to 3 (normal performance). All items can be performed by a healthy five-year-old child. Scores on each dimension are expressed in percentage. The total score is obtained by the sum of the five dimensions, which allows each part to contribute equally to the total score, from 0 to 100 .

\section{Cognitive function assessment}

Cognitive assessment was performed by a neuropsychologist. Raven's Colored Progressive Matrices were used for children aged 5-12 years of age and Raven's Progressive Matrices were used for patients aged 13 or older ${ }^{15}$. To allow the comparison between both scales, the number of correct answers was divided by the number of questions of each test and shown as a percentage.

Raven's Colored Progressive Matrices consist of three series of 12 items and Raven's Progressive Matrices consist of five series of 12 items. In each series, the questions show a progressive increase in the level of difficulty. Each item shows a figure with a part missing. The patient must indicate one of six or eight alternatives to complete the figure ${ }^{15}$.

\section{Functional independence assessment}

Functional independence was evaluated with the $\mathrm{PEDI}^{16}$. It measures the functional abilities and the caregiver assistance. It has three domains: self-care (PEDI-SC), mobility (PEDI-M) and social function (PEDI-SF). The PEDI was originally proposed to assess children between six months and seven years old. However, the development of 
scaled scores (used in the present study) made it viable for patients with functional difficulties aged up to 20 years ${ }^{17,18}$. Parents/caregivers are interviewed.

\section{Quality of life assessment}

Quality of life was measured by the Autoquestionnaire Qualité de vie Enfant Imagé (AUQEI). It has been validated in Brazil $^{19}$. It allows the self-evaluation of quality of life using four images of faces (very unhappy, unhappy, happy, very happy). It has 26 questions and the child is asked to say how he feels about daily life situations. Questions include family, social, activity, body functions and health relations. Each question is scored from 0 (very unhappy) to 3 (very happy). The maximum possible score is 78 and cutoff score is 48 . Bellow this score, the quality of life is considered reduced.

\section{Hydrocephalus}

Hydrocephalus was assessed by chart review. Patients were subdivided in two groups, according to the presence or absence of hydrocephalus.

\section{Statistical analysis}

The software Statistica 12.0 was used to run descriptive analyses of the lesion level, IQ, gross motor function (GMFM), cognitive performance (Raven matrices), functional independence (PEDI) and quality of life (AUQEI). Normality tests were run and the data showed non-normal distribution. No patient had missing data.

Friedman ANOVAs were run to determine a possible influence of hydrocephalus on gross motor function, cognition, functional independence and quality of life. The sample was subdivided in two groups (with, and without, hydrocephalus) and performances on tests were compared.

Spearman's correlation tests investigated the relationships between lesion level, gross motor function, cognition, functional independence and quality of life. Correlations were classified as strong when higher than 0.70 , moderate when between 0.40 and 0.70 and weak when lower than 0.40 . For all comparisons, the significance level was $\mathrm{p}<0.05$.

\section{RESULTS}

The main patient characteristics are shown in Table 1. Scores on scales are shown in Table 2.

The median on the GMFM was $64.9 \%$, ranging from $12.7 \%$ to $100 \%$. The median on Raven's tests was $55 \%$, ranging from $14 \%$ to $88 \%$. The median on PEDI was $67.6 \%(44.4 \%$ to $100 \%)$ in self-care domain; $66.2 \%(15.2 \%$ to $100 \%)$ in the mobility domain and 70.8 (43.8\% to $100 \%)$ for social function. The median on AUQEI was 76 (62 to 91).

Variables showed significant positive correlations with each other $(p<0.05)$. Table 3 shows the Spearman's coefficients. The GMFM was strongly related to mobility (PEDI-M) $(\mathrm{r}=0.925)$ and moderately related to self-care (PEDI-SC) $(\mathrm{r}=0.654)$, social function (PEDI-SF) $(\mathrm{r}=0.603)$ and cognition (Raven's progressive matrices) $(r=0.493)$. Lesion level was strongly correlated with the GMFM $(r=0.915)$ and mobility $(\mathrm{r}=0.830)$ and moderately correlated with self-care $(\mathrm{r}=0.582)$ and social function $(\mathrm{r}=0.529)$.

Cognition (Raven's progressive matrices) was moderately related to self-care $(r=0.410)$, mobility $(r=0.496)$ and social function $(r=0.465)$. Self-care, mobility and social function were strongly related to each other and social function was moderately related to AUQEI $(r=0.488)$. Age was moderately correlated with self-care $(r=0.409)$, social function $(r=0.683)$ and quality of life $(r=0.457)$.

When the sample was subdivided in two groups (with, and without, hydrocephalus) and performances on tests were compared with the Friedman ANOVAs, hydrocephalus negatively influenced the gross motor function $(p<0.001)$ and cognition $(p=0.04)$. Patients with hydrocephalus showed poorer motor and cognitive performance. They also had lower functional independence. The hydrocephalus group had lower scores on self-care $(p=0.017)$, mobility $(p<0.001)$ and social function $(\mathrm{p}=0.013)$ domains of PEDI. The quality of life did not differ between patients with, and without, hydrocephalus $(\mathrm{p}=0.478)$.

Table 1. Demographic and neurological characteristics $(n=47)$.

\begin{tabular}{lc}
\hline Sex, female (\%) & $22(47 \%)$ \\
\hline Age, median (min-max) & $10(5-20)$ \\
\hline Lesion level, (\%) & $15(32 \%)$ \\
\hline Thoracic & $7(15 \%)$ \\
\hline High lumbar & $12(25 \%)$ \\
\hline Low lumbar & $13(28 \%)$ \\
\hline Sacral & $34(72 \%)$ \\
\hline Hydrocephalus, yes (\%) & $34(72 \%)$ \\
\hline Ventriculoperitoneal shunt, yes (\%) & $100(67-124)$ \\
\hline Cognition (IQ), median (min-max)
\end{tabular}

min: minimal, max: maximum; IQ: intelligent quocient.

Table 2. Scores on motor and cognitive functions, functional independence and quality of life $(n=47)$.

\begin{tabular}{lc}
\hline Cognitive and motor scores & $\%$ (min-max) \\
\hline Raven's Matrices (correct answers) & $55(14-88)$ \\
\hline GMFM (motor total score) & $64.9(12.7-100)$ \\
\hline PEDI-SC & $67.6(44.6-100)$ \\
\hline PEDI-M & $66.2(15.2-100)$ \\
PEDI-SF & $70.8(43.8-100)$ \\
AUQEI & $67(62-91)$ \\
\hline $\begin{array}{l}\text { GMFM: Gross Motor Function Measure; PEDI: Pediatric Evaluation of } \\
\text { Disability Inventory SC: self-care; M: mobility; SF: social function; AUQEl: Auto } \\
\text { questionnaire Qualité de vie Enfant Imagé; min: minimum value observed, } \\
\text { max: maximum value observed. }\end{array}$
\end{tabular}


Table 3. Spearman's correlation coefficients between motor and cognitive functions, functional independence and quality of life $(\mathrm{n}=47)$.

\begin{tabular}{|c|c|c|c|c|c|c|c|}
\hline Variable & $\begin{array}{c}\text { R coefficient/ } \\
\mathrm{p} \text {-value }\end{array}$ & GMFM & Raven & PEDI-SC & PEDI-M & PEDI-SF & AUQEI \\
\hline \multirow{2}{*}{ Age } & $\mathrm{R}$ & 0.165 & 0.324 & $0.409 *$ & 0.322 & $0.683^{*}$ & $0.457 *$ \\
\hline & $P$ & 0.268 & 0.026 & $0.004^{*}$ & 0.027 & $<0.001^{*}$ & $0.001 *$ \\
\hline \multirow{2}{*}{ Lesion level } & $\mathrm{R}$ & $0.915^{\star \star}$ & 0.381 & $0.582^{\star}$ & $0.830 * \star$ & $0.529 \star$ & 0.284 \\
\hline & $P$ & $<0.001^{* *}$ & 0.008 & $<0.001 *$ & $<0.001 * \star$ & $<0.001^{*}$ & 0.053 \\
\hline \multirow{2}{*}{ Raven } & $\mathrm{R}$ & $0.492 *$ & - & $0.410 *$ & $0.496^{\star}$ & $0.465 *$ & 0.245 \\
\hline & $P$ & $0.001 *$ & - & $0.004^{\star}$ & $0.001 *$ & $0.001 *$ & 0.097 \\
\hline \multirow{2}{*}{ GMFM } & $\mathrm{R}$ & - & $0.492^{\star}$ & $0.654^{\star}$ & $0.925 * \star$ & $0.603^{*}$ & 0.304 \\
\hline & $P$ & - & $0.001 *$ & $<0.001 *$ & $<0.001 * \star$ & $<0.001 *$ & 0.038 \\
\hline \multirow{2}{*}{ PEDI-SC } & $\mathrm{R}$ & $0.654^{*}$ & $0.410^{*}$ & - & $0.765 * *$ & $0.743 * *$ & 0.318 \\
\hline & $P$ & $<0.001 *$ & $0.004^{*}$ & - & $<0.001 * *$ & $<0.001 * *$ & 0.029 \\
\hline \multirow{2}{*}{ PEDI-M } & $\mathrm{R}$ & $0.925 * *$ & $0.496 *$ & $0.765^{\star *}$ & - & $0.754 * *$ & 0.387 \\
\hline & $P$ & $<0.001 * *$ & $0.001^{*}$ & $<0.001^{\star *}$ & - & $<0.001^{\star *}$ & 0.007 \\
\hline \multirow{2}{*}{ PEDI-SF } & $\mathrm{R}$ & $0.603 *$ & $0.465^{\star}$ & $0.743 * \star$ & $0.754 * \star$ & - & $0.488 *$ \\
\hline & $P$ & $<0.001 *$ & $0.001 *$ & $<0.001 \star \star$ & $<0.001 * \star$ & - & 0.001 \\
\hline
\end{tabular}

${ }^{\star}$ moderate relationships ${ }^{*}$ strong relationships. Raven: Raven's Colored Progressive Matrices and Raven's Progressive Matrices; GMFM: Gross Motor Function Measure (\%); PEDI: Pediatric Evaluation of Disability Inventory; SC: self-care; M: mobility; SF: social function;AUQEl: Auto questionnaire Qualité de vie Enfant Imagé.

\section{DISCUSSION}

The present study described many moderate relationships between gross motor function, cognition, functional independence and quality of life in patients with MMC.

\section{Relationship between gross motor function and cognition}

A huge variability was observed in the GMFM scores. This large motor function variability among patients with MMC has been previously documented. Variability was observed even in patients with the same lesion level ${ }^{10,11}$. In the present study, the lesion level was strongly correlated with gross motor function and mobility, which partially contradicts this statement and reinforces that the lesion level is highly related to gross motor function.

Motor deficits seem to emerge not only from spine lesion, but also from brain areas, such as the cerebellum and brainstem. Patients with MMC with a motor level below L3 had better physical function compared with those with a higher lesion level. According to Sibinski et al., the motor level was the only factor found to affect physical function ${ }^{20}$. These findings corroborate our results, because the GMFM was strongly correlated with the lesion level and with the PEDI mobility section.

The Raven's test median was lower than scores expected for healthy children/adolescents. Previous studies have described cognitive deficits in patients with $\mathrm{MMC}^{8,10,11}$. However, no previous studies provided descriptive data about the performance of patients with MMC on Raven's tests. The influence of hydrocephalus on cognitive outcomes of patients with MMC is controversial in the literature. Some studies showed that the association of MMC with hydrocephalus influenced cognition negatively. Patients with MMC with hydrocephalus showed lower scores on executive function in some studies ${ }^{7,8}$. However, in other studies, this association was not observed ${ }^{6}$.
We found moderate correlation between gross motor function and cognition. Even the children with discrete clinical manifestations of MMC tend to have fewer motor resources available to explore the environment. It is harder for them to find out the best ways of acquiring sensory information and selecting motor responses; therefore, they are more likely to fail when creating/selecting internal models. They may receive less stimulation, which disrupts sensorimotor learning ${ }^{10}$.

The direct association between motor abilities and cognition has scarcely been investigated. No study has applied a gross motor scale so far. Instead, the lesion level, functional independence or ability to ambulate were used as references. The lesion level was reported as not being associated with cognitive impairments ${ }^{6,21}$ and a weak correlation between the lesion level and cognition was found in the present study.

Vinck et al. found a correlation between fine motor function and cognition of children with MMC. They assessed patients with the Movement Assessment Battery - fine skills subitems ${ }^{22}$. The present study complements these data with the GMFM, showing that gross motor function is less related to cognition than fine motor function.

\section{The relationship between gross motor function, functional independence and quality of life}

As in the GMFM, a great variability was observed in the PEDI (scaled scores). Motor function was strongly related to mobility and moderately related to self-care, social function and cognitive performance. These findings corroborate previous studies, which have also shown moderate-to-strong relationships between motor functions and functional independence in children with $\mathrm{MMC}^{2,3,1,2,23}$.

Self-care, mobility and social function were strongly related to each other and social function was moderately related to quality of life. Sibinski et al. ${ }^{20}$ investigated the relationship between the quality of life and the overall physical function in 
patients with MMC. They found no association between spinal deformity and self-perception, motivation and physical function. They reported that patients with more severe scoliosis had a lower quality of life, which, in turn, was also related to the age of the patients. The present study found moderate relationships between age and quality of life, self-care and social function, which agrees with the results of Sibinski et al. ${ }^{20}$.

\section{The relationship between cognitive performance and functional independence}

Cognitive performance was moderately related to all the domains of the PEDI: self-care, mobility and social function. The PEDI has previously been used in studies with children with MMC. It was found to be related to the lesion level ${ }^{24}$, which was also found in the present study, with moderate relationships between the lesion level and self-care and social function domains and a strong correlation between lesion level and mobility.

The PEDI has also been shown to be related to ambulatory and cognitive performances ${ }^{23}$. More functional patients had better cognitive performance, executive and visuospatial skills ${ }^{17}$. Barf et al. ${ }^{24}$ showed that cognitive performance was strongly correlated with all sub items of the Functional Independence Measure. The same results were obtained in the present study, because, as mentioned before, the cognitive performance, measured by Raven's matrices, was moderately related to all domains of the PEDI.

Verhoef et al. ${ }^{25}$ concluded that only hydrocephalus and the lesion level determined the ambulation capacity, the ability to transfer and self-care. We found that the lesion level was strongly related to the motor function and mobility and we found a moderate relation between motor function and self-care. Hydrocephalus influenced motor and cognitive functions negatively. Also, lower functional outcomes were observed for the hydrocephalus group, which agrees with the study of Verhoef et al.
The relationship between quality of life, cognitive performance and functional independence

The quality of life was moderately correlated with age and social function. Although the cognitive performance has previously been found to have a higher correlation with the quality of life than the functional independence in patients with $\mathrm{MMC}^{24}$, in the present study, the quality of life and the cognitive performance were weakly correlated. However, it is important to mention that patients with lower cognitive performance may have provided less accurate answers in the quality of life questionnaire, and future studies should address such difficulties in evaluation.

Several studies have investigated functional independence and the quality of life in patients with MMC. Schoenmakers et al. ${ }^{18}$ observed that the quality of life highly impacts mobility. Mobility, in turn, is determined by the cognitive performance, the muscle strength and the degree of contractures found in the lower limbs. Therefore, mobility seems to be more relevant to the quality of life than other functional skills, such as self-care performance or wheelchair dependence. The present study contradicts this statement, as the quality of life was moderately related to social function and weakly related to gross motor function, cognitive performance, self-care and mobility. According to our findings, patients with severe lesions and poor outcomes can have a higher quality of life if they have an adequately-developed social function.

As limitations, the GMFM has not been validated specifically for patients with MMC, although some studies have used this instrument with this population with good responsiveness and usability. Our sample included a broad variety of ages and outcomes, which provides generality to the results.

Gross motor function, cognition, functional independence and quality of life showed moderate and strong correlations. These aspects should further be evaluated to allow more accurate assessment and better outcomes in patients with MMC.

\section{References}

1. Fletcher JM, Copeland K, Frederick JA, Blaser SE, Kramer LA, Northrup $\mathrm{H}$ et al. Spinal lesion level in spina bifida: a source of neural and cognitive heterogeneity. J Neurosurg. 2005;102(3 Suppl):268-79. https://doi.org/10.3171/ped.2005.102.3.0268

2. Bartonek A, Saraste H, Danielsson A. Health-related quality of life and ambulation in children with myelomeningocele in a Swedish population. Acta Paediatr. 2012;101(9):953-6. https://doi.org/10.1111/j.1651-2227.2012.02742.x

3. Bartoneck A, Saraste H. Factors influencing ambulation in myelomeningocele: a cross-sectional study. Dev Med Child Neurol. 2001;43(4):253-60. https://doi.org/10.1017/S0012162201000482

4. Christensen C, Lowes, LP. Treadmill training for a child with spina bifida without functional ambulation. Pediatr Phys Ther. 2014;26(2):265-73. https://doi.org/10.1097/PEP.0000000000000029

5. Lynch A, Ryu JC, Agrawal S, Galloway JC. Power mobility training for a 7-month-old infant with spina bifida. Pediatr Phys Ther. 2009;21(4):362-8. https://doi.org/10.1097/PEP.0b013e3181 bfae4c
6. Roebroeck ME, Hempenius L, Baalen B, Hendriksen JG, Berg-Emons HJ, Stam HJ. Cognitive functioning of adolescents and young adults with meningomyelocele and level of everyday physical activity. Disabil Rehabil. 2006;28(20):1237-42. https://doi.org/10.1080/09638280600551716

7. Lindquist B, Uvebrant P, Rehn E, Carlsson G. Cognitive functions in children with myelomeningocele without hydrocephalus. Childs Nerv Syst. 2009;25(8):969-75. https://doi.org/10.1007/s00381-009-0843-5

8. Iddon JL, Morgan DJ, Loveday C, Sahakian BJ, Pickard JD. Neuropsychological profile of young adults with spina bifida with or without hydrocephalus. J Neurol Neurosurg Psychiatry. 2004;75(8):1112-8. https://doi.org/10.1136/jnnp.2003.029058

9. Hetherington R, Dennis M, Barnes M, Drake J, Gentili F. Functional outcome in young adults with spina bifida and hydrocephalus. Childs Nerv Syst. 2006;22(2):117-24. https://doi.org/10.1007/s00381-005-1231-4 
10. Dennis M, Barnes MA. The cognitive phenotype of spina bifida meningomyelocele. Dev Disabil Res Rev. 2010;16(1):31-9. https://doi.org/10.1002/ddrr.89

11. Dennis M, Landry SH, Barnes M, Fletcher JM. A model of neurocognitive function in spina bifida over the life span. J Int Neuropsychol Soc. 2006;12(2):285-96. https://doi.org/10.1017/S1355617706060371

12. Sirzai H, Dogu B, Demir S, Yilmaz F, Kuran B. Assessment on self-care, mobility and social function in children with spina bifida in Turkey. Neural Regen Res. 2014;9(12):1234-40. https://doi.org/10.4103/1673-5374.135332

13. Wang JC, Lai CJ, Wong TT, Liang ML, Chen HH, Chan RC et al. Health-related quality of life in children and adolescents with spinal dysraphism: results from a Taiwanese sample. Childs Nerv Syst. 2013;29(9):1671-9. https://doi.org/10.1007/s00381-013-2117-5

14. Russell DJ, Rosenbaum PL, Cadman DT, Gowland C, Hardy S, Jarvis S. The gross motor function measure: a means to evaluate the effects of physical therapy. Dev Med Child Neurol. 1989;31(3):341-52. https://doi.org/10.1111/j.1469-8749.1989.tb04003.x

15. Raven JC, Raven J, Court JH. Matrizes progressivas coloridas de Raven: manual. São Paulo: Casa do Psicólogo; 1988.

16. Ziviani J, Ottenbacher KJ, Shephard K, Foreman S, Astbury W, Ireland P. Concurrent validity of the Functional Independence Measure for Children (WeeFIM) and the pediatric evaluation of disabilities inventory in children with developmental disabilities and acquired brain injuries. Phys Occup Ther Pediatr. 2001;21(2-3):91-101. https://doi.org/10.1080/J006v21n02_08

17. Norrlin S, Strinnholm M, Carlsson M, Dahl M.

Factors of significance for mobility in children with myelomeningocele. Acta Paediatr. 2003;92(2):204-10. https://doi.org/10.1111/j.1651-2227.2003.tb00527.x
18. Schoenmakers MA, Gulmans VA, Gooskens RH, Pruijs JE, Helders PJ. Spinal fusion in children with spina bifida: influence on ambulation level and functional abilities. Eur Spine J. 2005;14(4):415-22. https://doi.org/10.1007/s00586-004-0768-3

19. Assumpção Junior FBJ, Kuczynski E, Sprovieri MH, Aranha EMG. [Quality of life evaluation scale (AUQEI): validity and reliability of a quality of life scale for children from 4 to 12 years-old]. Arq Neuro-Psiquiatr. 2000;58(1):119-27. Portuguese. https://doi.org/10.1590/S0004-282X2000000100018

20. Sibinski M, Synder M, Higgs ZC, Kujawa J, Grzegorzewski A. Quality of life and functional disability in skeletally mature patients with myelomeningocele-related spinal deformity. J Pediatr Orthop B. 2013;22(2):106-9. https://doi.org/10.1097/BPB.0b013e32835c2a65

21. Davis BE, Shurtleff DB, Walker WO, Seidel KD, Duguay S. Acquisition of autonomy skills in adolescents with myelomeningocele. Dev Med Child Neurol. 2006;48(4):253-8. https://doi.org/10.1017/S0012162206000569

22. Vinck A, Nijhuis-van der Sanden MW, Roeleveld NJ, Mullaart RA, Rotteveel JJ, Maassen BA. Motor profile and cognitive functioning in children with spina bifida. Eur J Paediatr Neurol. 2010;14(1):86-92. https://doi.org/10.1016/j.ejpn.2009.01.003

23. Tsai PY, Yang TF, Chan RC, Huang PH, Wong TT. Functional investigation in children with spina bifida, measured by the Pediatric Evaluation of Disability Inventory (PEDI). Childs Nerv Syst. 2002;18(1-2):48-53. https://doi.org/10.1007/s00381-001-0531-6

24. Barf HA, Post MW, Verhoef M, Gooskens RH, Prevo AJ. Is cognitive functioning associated with subjective quality of life in young adults with spina bifida and hydrocephalus? J Rehabil Med. 2010;42(1):56-9. https://doi.org/10.2340/16501977-0481

25. Verhoef M, Barf HA, Post MW, Asbeck FW, Gooskens RH, Prevo AJ. Functional independence among young adults with spina bifida, in relation to hydrocephalus and level of lesion. Dev Med Child Neurol. 2006;48(2):114-9. https://doi.org/10.1017/S0012162206000259 